Cite this paper as:

Ukpabi D.C., Karjaluoto H., Olaleye S., Mogaji E. (2020) Customer Value Framework and Recommendation Intention: The Moderating Role of Customer Characteristics in an Online Travel Community. In: Neidhardt J., Wörndl W. (eds) Information and Communication Technologies in Tourism 2020. Springer, Cham. DOI https://doi.org/10.1007/978-3-030-36737-4_4

\title{
Customer value framework and recommendation intention: The moderating role of customer characteristics in an online travel community
}

\begin{abstract}
The aim of this study is to develop and test a model that examines the interactions among customer value framework, recommendation intention and customer characteristics in an online travel community (OTC). Data was obtained from Amazon Mechanical Turk with 251 members of OTC as sample. Partial least squares was used to analyse the data. We found that all the variables of customer value framework, namely functional value, hedonic value and social value were positively related to recommendation intention. In addition, using multi-group analyses, the study found differences between how different customer segments perceive each of the value dimensions and their effect on recommendation intention. Theoretical and managerial implications are offered.
\end{abstract}

\section{Introduction}

Online travel communities (OTCs) provide consumers the platform to share travel experiences $(\mathrm{Ku}, 2011)$. Due to the value consumers get from the platform, it has become a critical information source for travel decision (Jung, Lee, Hur and Kim, 2018). Consumers are motivated to participate in these platforms based on the value they derive from them. For instance, while those who join travel booking sites are motivated by the informational content, that is, quality of reviews including information on the brand's or destination offering and attractiveness (Lee, Law and Murphy, 2011; Kavoura and Borges 2016), community members on social networking and blogsites are motivated by social, hedonic and altruistic value (Ben-Shaul and Reichel, 2018; Lee and Hyun, 2018).

Consumer behavior theorists argue that consumer needs and preferences underlie value perceptions (Smith and Colgate, 2007). Thus, customer value framework has been conceptualized to clarify the understanding and enhance the measurement of customer value (Jung-Choo, Moon, Kim and Yoon, 2012). Components of customer value varies across different contexts, however, there seems to be a consensus in consumer behavior literature which typifies customer value into functional, social and hedonic value (Smith and Colgate, 2007; Jung-Choo, Moon, Kim and Yoon, 2012; Zhang, Guo, Hu and Liu, 2017). Several studies have linked customer value to positive word of mouth or recommendation intention (Shi, Tang, Zhang, Gao and Zhu, 2016; Zhang, Guo, Hu and Liu, 2017). In the OTC literature, a positive association exists between customer value and continuous participation (Ukpabi, Karjaluoto, Olaleye, \& Mogaji, 2019). Additionally, consumer characteristics have been found to play different roles in different consumption contexts. For instance, Chan, Cheung, Shi and Lee (2015) found that male and female differed significantly with satisfaction, relationship maintenance, entertainment and disconfirmation of entertainment with Facebook. Understanding how customer value impacts recommendation intention in OTCs is critical because the sustainability of OTCs depends on new members who join the platform and the significant number of the new members were motivated by the recommendations of existing users 
(Li, Lee and Yang, 2019). Accordingly, this study has two main objectives, namely; to examine the effect of customer value framework on recommendation intention and to understand the role of customer value framework on participant's characteristics in relation to recommendation intention.

\section{Consumer Value Framework}

Consumer value is considered the overall assessment of the utility of a product based on perceptions of what is received and what is given (Zeithaml, 1988). Holbrook (2005, p. 46) defines customer value as an "interactive, relativistic preference and experience". Smith \& Colgate (2007) recognised the inconclusive effort towards properly describing what consumer value entails, as it was not clear whether customer value is a summative (benefits/fewer sacrifices) or ratio (benefits divided by sacrifices) based evaluation, they drew on, integrated and extended previous conceptual foundations of customer value to develop the customer value framework. The framework identifies four major types of value that can be created by organizations - functional/instrumental value, experiential/hedonic value, symbolic/expressive value, and cost/sacrifice value. A recent study has made an effort to develop a better understanding of the framework. $\mathrm{Xu}$, et al, (2015) posited that consumer value involves a trade-off process where customers evaluate the benefits received and the sacrifices given from using a product/service, the benefits are either utilitarian benefits, hedonic benefits and monetary sacrifices and non-monetary sacrifices. This was further reiterated by Zhang, et al., (2017) who defined consumer value as the process by which producers and consumers, as peer subjects, co-create value for themselves and each other and presented customer value creation as a three-dimensional construct, having functional, hedonic, and social value.

Functional value is based on the assumption that individuals are rational problem solvers (Zhang, et al., 2017). From the perspective of OTCs, functional value encompasses their members' need for information that leads to financial savings and high quality of service. It also recognises the desired characteristics of the OTC which makes it more encouraging to use (Smith \& Colgate, 2007). Functional value is derivable if the OTCs has the appropriate features, functions, attributes, appropriate performances (such as reliability, performance) and appropriate outcomes and operational benefits (Zhang, et al., 2017). On the other hand, social value is considered an independent dimension in total customer value that is used to enhance user status and self-esteem (Rintamäki, et al., 2006). These value offers are derived as evidence of a long-term engagement within the community; they represent a symbolic status used to emphasize unique traits (Rintamäki, et al., 2006). Social value closely relates to the symbolic and expressive value of the OTCs which highlights the extent to which users attach or associate psychological meaning to their engagement in the community (Smith \& Colgate, 2007). Previous research has only focused on online engagement for co-creating consumer value, but little is known about its influence on recommendation intention in an OTC. Finally, hedonic value has been conceptualized as the feelings and emotive aspects of community involvement (Wang, 2016). It represents the extent to which the OTCs creates appropriate experiences, feelings, and emotions for the users (Smith \& Colgate, 2007). Lee \& Hyun (2015) report that enjoyable features are critical in influencing participation levels in OTCs. A recent study (Li, Lee and Yang, 2019) also found that 
consumer recommendations influence visit intention. Thus, we argue that incorporating enjoyable features leading to fun and pleasure in the OTC will lead to recommendation intention.

While customer segmentation has been performed mainly based on gender, it is essential to recognise that gender refers to psychological features related to biological nature and sociological variables (Deshwal, 2016), which are different for both male and female. Studies showed that there are differences in how men and women think and behave based on their role in society (Yildirim, et al., 2014). Research on gender differences has suggested that male and female possess different attitudes and preferences in using different information systems (Debrand \& Johnson, 2008). Kim, et al (2012) recognises that these attributes can influence behaviours and attitudes of each gender differently regarding consumption activities. Yang and Lee (2010) also found that female consumers are more likely to look for the hedonic value as they are sensitive, intuitive, passionate, communal goal-oriented, and linked with femininity. Female are relational oriented, they like to maintain ties, connecting with friends and engage in social activities (Chan, et al., 2015). Male consumers, however, are more likely to look for functional value as they tend to be independent, rational, individual goal-oriented (Yang \& Lee, 2010) and they are more rational and focus more on task-oriented activities (Chan, et al., 2015). Age has been used as a variable to ascertain how individuals evaluate the value from their experience with brands (Deshwal, 2016). Several studies have shown that patterns of consumption differ significantly between age group (Kim, et al., 2012). While young consumers are low-income consumers and less experienced in product purchasing compared to older consumers, they exhibit quite different and distinctive online shopping patterns (Kim, et al., 2012) and information searching process. Young people are more likely to engage CGM when planning their vacation trips than older people (Mogaji \& Erkan, 2019) however, since the older consumers have more circle of friendships, they are more likely to recommend the OTCs when their information needs are met.

Customers who perceive they obtain greater value from using a service to be more satisfied with it and continue to use it (Xu, et al., 2015), the time spent in engaging with other users on the OTCs is important towards its survival (Ukpabi, et al., 2019) suggesting the need to make it more valuable for the users. Individuals participate in social networks due to perceived value as hedonic value, utilitarian value, and social value (Yu, et al., 2013). Likewise, stickiness has been considered an important behavioural outcome to consider in online communities (Lee \& Hyun, 2015). This is considered an integrated index for measuring individuals' duration of staying in online communities, frequency of visits and willingness to revisit (Dubelaar, et al., 2003; Elliot, et al., 2013) which help ensure a longer period of participate in the community activities and interacting with other members in the community (Lin, 2007; Tsai, et al., 2012). Taking into consideration that OTCs are relationship-centric and inherently participatory (Tsai \& Men, 2013), adequate sharing of travel information and knowledge is a fundamental concern since the community cannot exist, let alone be vibrant or effective, without it the engagement (Lee, et al., 2014). Likewise, the users' perception of hedonic and utilitarian value offers in the OTCs is considered a component of customer satisfaction and 
form positive loyalty (frequency of visits to online virtual communities) (Kim, et al., 2012). The value offers inherent in the OTCs should make individuals engage within the community and encourage them to continually use the brand. Thus, we propose that:

H1. Perceived functional value of OTCs is positively related to recommendation intention

H2. Perceived hedonic value of OTCs is positively related to recommendation intention.

H3. Perceived social value of OTCs is positively related to recommendation intention.

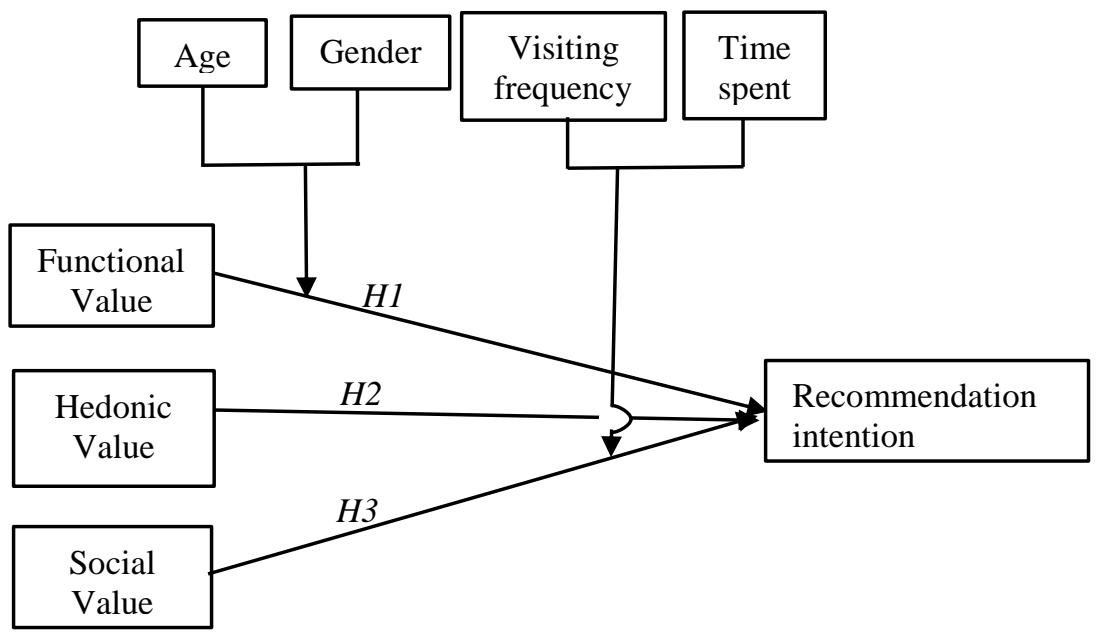

Figure 1. Conceptual framework of our study

\section{Research methodology}

The study utilised existing validated measures and modified the wording of items to suit the context of our study. The items for functional, social and hedonic value and recommendation intention were adapted from Zhang et al. (2017). The study measured items on a seven-point Likert scales with "strongly disagree (1)" as the lowest and "strong agree (7)" as the highest. Table 1 shows the details of the measurement items.

Table 1. Online Travel Community Measurement Indicators

\begin{tabular}{ll}
\hline Latent Variables & Indicators \\
\hline Functional Value (FV) & FV1. The content (information) in this online \\
$\left(\mathbf{0 . 7 1} ; \mathbf{0 . 8 8 ^ { b }}\right)$ & travel community is helpful for me $(\mathbf{0 . 8 9})$ \\
& *FV2. The content (information) in this online \\
& travel community is useful for me \\
& FV3. The content (information) in this online \\
& travel community is functional for me $(\mathbf{0 . 8 6})$ \\
\hline
\end{tabular}


FV4. The content (information) in this online travel community is practical for me $\left(\mathbf{0 . 7 9}^{\mathrm{c}}\right)$

Hedonic Value (HV)

$\left(0.78^{\mathrm{a}} ; 0.88^{\mathrm{b}}\right)$

Social Value (SV)

$\left(0.82^{\mathrm{a}} ; 0.93^{\mathrm{b}}\right)$
*HV1. I feel pleased and relaxed in this online travel community

HV2. I gain joy and happiness in this online travel community $\left(0.88^{\mathrm{c}}\right)$

HV3. I feel inspired in this online travel community $\left(0.88^{c}\right)$

SV1. I can make friends with people sharing common interests with me in this online travel community $\left(0.90^{\circ}\right)$

SV2. This online travel community helps strengthen my connections with other members $\left(0.89^{\mathrm{c}}\right)$

SV3. I can expand my social network through participation in this online travel community $\left(0.92^{\mathrm{c}}\right)$

Recommendation Intention RI1. I would recommend this online travel com(RI)

$\left(0.72^{\mathrm{a}} ; 0.89^{\mathrm{b}}\right)$

munity to friends $\left(0.86^{c}\right)$

*RI2. I will participate in this online travel community the most than in others

RI3. I will say positive things about this online community to other people $\left(0.89^{c}\right)$

RI4. I would encourage friends and relatives to do business with the brand of this online community $\left(0.79^{c}\right)$

* Removed indicators $<0.5$

*Average Variance Extracted ${ }^{\mathrm{a}}$; Composite Reliability ${ }^{\mathrm{b}}$; Item Loadings ${ }^{\mathrm{c}}$

The data for the online travel community study was collected online through the crowdsourcing of Amazon Mechanical Turk (MTurk). The study opted for the MTurk because of its low cost and limited time in data collection. Further, its validity has been scrutinised in the study of Berinsky, Huber and Lenz, (2012) and the authors explained its peculiar benefits for social science research. Out of 253 responses received in August 2018 , only two cursory responses were deleted, and 251 valid responses were used for the data analysis. Among the respondents, 165 males participated with $66 \%$ and 86 females with 34\%. The age bracket 19 - 60 was divided into young and old class. 122 accounts for the young group with $49 \%$ and 129 old group with $51 \%$. Visiting frequency was classified into high and less frequency. 116 respondents accounts for high frequency with $46 \%$ and 135 less frequency with 54\%. Also, average time spent was grouped into high and low users. 61 responses accounts for high users with $24 \%$ and 190 low users with $76 \%$ (Table 2). 
Table 2. Online Travel Community Respondent descriptive statistics

\begin{tabular}{llll}
\hline Descriptive & Classification & Frequency & Percentage \\
\hline \multirow{2}{*}{ Gender } & Male & 165 & 66 \\
& Female & 86 & 34 \\
Age & Young & 122 & 49 \\
& Old & 129 & 51 \\
Visiting Frequency & Frequent & 116 & 46 \\
& Infrequent & 135 & 54 \\
\multirow{2}{*}{ Average Time Spent } & Longer time & 61 & 24 \\
& Lesser time & 190 & 76 \\
\hline
\end{tabular}

\section{Data analysis}

The study used SmartPLS version 3 with Structural Equation Modelling (SEM) approach (Ringle, Wende and Becker, 2015). SmartPLS software is appropriate for both reflective and formative data analysis. Additionally, Hair, Ringle and Sarstedt (2011) contend that PLS-SEM and CB-SEM are complementary rather than competitive. Thus, PLS-SEM is recommended for predicting or identifying key target construct or drivers. Comparing with covariance SEM, SmartPLS is preferable for this study because it simplified the issue of sample size (Chin and Newsted, 1999; Dijkstra, 2014). With SmartPLS software, the study assesses the measurement scales and examined the structural model (Hair, Sarstedt, Ringle and Gudergan, 2018). Further, the study embarked on reliability and validity test of the measurement model. Composite reliability (CR) as a reliability criterion as shown in Table 1 are all above the verge of 0.70 as recommended by Fornell and Larcker (1981). Composite reliability and average variance extracted (AVE) as criteria for convergent validity were of high quality. Composite reliability values are all higher than 0.70 and AVE for each latent variable are greater than the threshold of 0.50 (Hair, et al. 2018). In all, the result reveal acceptable convergent validity of the measurements. Discriminant validity as suggested by Fornell and Larcker, (1981) should reflect that the square root of AVE diagonally is greater than the correlation under the latent variables. In this study, the square root of AVE for the latent variable is greater than the correlations values under the constructs. The results suggest discriminant validity of the study measurements.

\section{Structural model analysis}

The study used bootstrapping technique with 5000 samples for the structural explanatory power and the structural model path significance (Sarstedt, Henseler and Ringle, 2011; Hair, et al. 2018). Specifically, the study tested the proposed model with five distinct samples, that is, the full sample, gender subsample, age subsample, frequency visit subsample and average time visit subsample. The original model explains $62 \%$ of the variance in recommendations intentions. In Tables 4 and 5, male and female had equal $\mathrm{R}^{2}(61 \%)$. Young $\mathrm{R}^{2}$ was $(68 \%)$ and higher than old $\mathrm{R}^{2}$, which accounts for $(56 \%)$. Also, the high frequency $\mathrm{R}^{2}$ was $(68 \%)$ and higher than the less frequency $\mathrm{R}^{2}(54 \%)$. Higher users record the highest $\mathrm{R}^{2}(82 \%)$ while the low users account for (56\%).Also, 
functional value has the highest $f^{2}(0.28)$ and $\mathrm{Q}^{2}(0.12)$. The result suggests that functional value has a moderate effect on recommendation intentions and the functional value has predictive relevance $\left(\mathrm{Q}^{2}\right)$ for the recommendation intention moderately (Hair, Hult, Sarstedt and Ringle, 2014). The hypotheses for the full model (H1-3) are significant at $\mathrm{p}<0.05$ and $\mathrm{p}<0.001$. Functional value $(\beta=0.44, \mathrm{p}<0.001)$, hedonic value $(\beta=0.36, p<0.001)$ and social value $(\beta=0.11, \mathrm{p}<0.05)$ with direct significant relationship with recommendation intentions (Figure 2 and Table 3 ).

Table 3. Online Travel Community Path Coefficient Analysis Result

\begin{tabular}{llllll}
\hline Hypotheses & Variable Relationship & Beta & Std.Dev. & t-values & Decision \\
\hline H1 & FV -> RI & 0.44 & 0.07 & $6.28^{* * *}$ & Accepted \\
H2 & HV -> RI & 0.36 & 0.06 & $5.97 * * *$ & Accepted \\
H3 & SV -> RI & 0.11 & 0.05 & $2.10^{*}$ & Accepted \\
\hline
\end{tabular}

Notes. Significant levels $* \mathrm{p}<0.05 ; * * * \mathrm{p}<0.001$

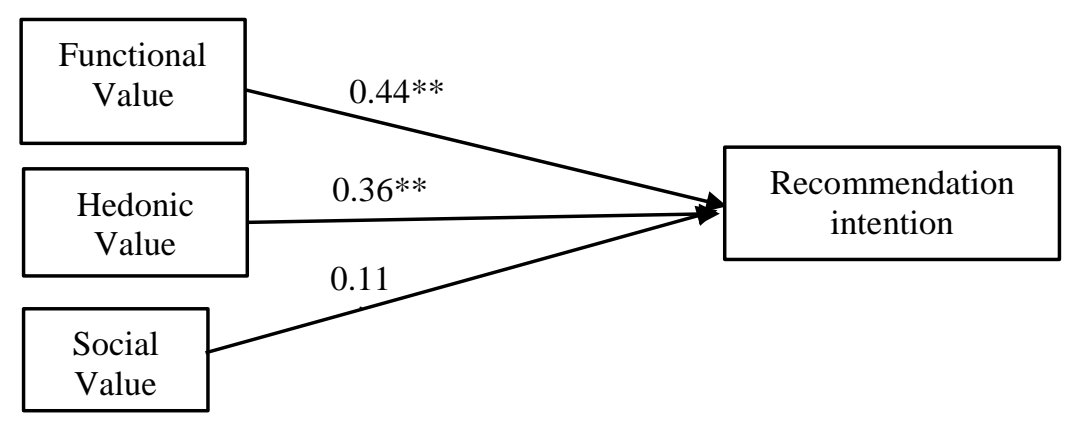

Figure 2. Partial Least Square Result of Full Sample

Notes. Significant levels $* \mathrm{p}<0.05 ; * * * \mathrm{p}<0.001$

The study conducted multi-group analysis for gender, age, frequency of visit and duration of visit (Table 4). The purpose of the multi-group analysis was to determine how the perception of value by the different customer segments would influence their recommendation intention Tables 4, 5 and 6). Thus, moderation result between the gender indicate that the influence of functional value on recommendation intention was stronger for male than female participants (male, $p<0.001$ and female, $p<0.001$ ). However, in our tests for the age group we proposed that the influences of functional value on recommendation intention was stronger with the older than younger participants, which was not accepted though significant (older, $\mathrm{p}<0.001$ and younger, $\mathrm{p}<0.001$ ).

Table 4. Online Travel Community Model Summary

\begin{tabular}{llllllllll}
\hline $\begin{array}{l}\text { Variable Rela- } \\
\text { tionship }\end{array}$ & $\begin{array}{l}\text { OS } \\
(\mathrm{n}=251)\end{array}$ & $\mathrm{f}^{2}$ & $\mathrm{q}^{2}$ & $\begin{array}{l}\text { Male } \\
(\mathrm{n}=165)\end{array}$ & $\begin{array}{l}\text { Fe- } \\
\text { male } \\
(\mathrm{n}=86)\end{array}$ & $\begin{array}{l}\text { Male } \\
\text { vs fe- } \\
\text { male } \\
(\mathrm{t}-\mathrm{value})\end{array}$ & $\begin{array}{l}\text { Young } \\
(\mathrm{n}=122)\end{array}$ & $\begin{array}{l}\text { Old } \\
(\mathrm{n}=129)\end{array}$ & $\begin{array}{l}\text { Young } \\
\text { vs old } \\
(\mathrm{t}-\mathrm{value})\end{array}$ \\
\hline $\begin{array}{l}\text { Functional Value } \\
\begin{array}{l}->\text { Recommenda- } \\
\text { tion Intention }\end{array}\end{array}$ & 0.44 & 0.28 & 0.12 & 0.46 & 0.42 & $6.966^{* * *}$ & 0.48 & 0.40 & $6.915^{* * * *}$ \\
\end{tabular}




\begin{tabular}{|c|c|c|c|c|c|c|c|c|c|}
\hline $\begin{array}{l}\text { Hedonic Value - } \\
\text { > Recommenda- } \\
\text { tion Intention }\end{array}$ & 0.36 & 0.14 & 0.06 & 0.34 & 0.39 & $6.321 * * *$ & 0.34 & 0.39 & $6.67 * * *$ \\
\hline $\begin{array}{l}\text { Social Value -> } \\
\text { Recommendation } \\
\text { Intention }\end{array}$ & 0.11 & 0.02 & 0.01 & 0.10 & 0.15 & $2.012^{*}$ & 0.12 & 0.10 & $2.14 *$ \\
\hline $\mathrm{R} 2$ & 0.62 & & & 0.61 & 0.61 & & 0.68 & 0.56 & \\
\hline
\end{tabular}

Notes: $0.02-0.15$ weak, $0.15-0.35$ moderate effect, $>0.35$ strong effect

Significant levels $* \mathrm{p}<0.05 ; * * * \mathrm{p}<0.001$

OS - original sample

Table 5. Online Travel Community Model Summary (cont'd)

\begin{tabular}{lllllll}
\hline Variable Relationship & $\begin{array}{l}\text { Fre. } \\
(\mathrm{n}=116)\end{array}$ & $\begin{array}{l}\mathrm{LF} \\
(\mathrm{n}=135)\end{array}$ & $\begin{array}{l}\text { Fre vs LF } \\
(\mathrm{t}-\mathrm{value})\end{array}$ & $\begin{array}{l}\mathrm{HU} \\
(\mathrm{n}=61)\end{array}$ & $\begin{array}{l}\mathrm{LU} \\
(\mathrm{n}=190)\end{array}$ & $\begin{array}{l}\text { HU vs LU } \\
(\mathrm{t}-\mathrm{value})\end{array}$ \\
\hline $\begin{array}{l}\text { Functional Value -> Rec- } \\
\text { ommendation Intention }\end{array}$ & 0.43 & 0.45 & $6.63^{* * *}$ & 0.69 & 0.39 & $6.561^{* * *}$ \\
$\begin{array}{l}\text { Hedonic Value -> Recom- } \\
\text { mendation Intention }\end{array}$ & 0.42 & 0.30 & $6.444^{* * *}$ & 0.18 & 0.39 & $6.139^{* * *}$ \\
$\begin{array}{l}\text { Social Value -> Recom- } \\
\text { mendation Intention }\end{array}$ & 0.11 & 0.12 & 1.95 & 0.09 & 0.10 & $2.015^{*}$ \\
$\mathrm{R} 2$ & $\mathbf{0 . 6 8}$ & $\mathbf{0 . 5 4}$ & & $\mathbf{0 . 8 2}$ & $\mathbf{0 . 5 6}$ & \\
\hline
\end{tabular}

Notes: $0.02-0.15$ weak, $0.15-0.35$ moderate effect, $>0.35$ strong effect

Significant levels $* \mathrm{p}<0.05 ; * * * \mathrm{p}<0.001$

$\mathrm{Fr}$ - frequent users; LF - low frequent users; HU - high users; LU - low users

Similarly, we tested for how hedonic and social value influence frequency and duration of visits in relation to recommendation intention (Tables 4, 5 and 6). Our results indicate that influences of hedonic value on recommendation intention are stronger for frequent visitors than infrequent visitors (frequent visitors, $\mathrm{p}<0.001$ and infrequent visitors, $\mathrm{p}<0.001$ ), while our assumption that influences of hedonic value on recommendation intention was stronger with those who spend more time than those who spend less time was not supported (more times, $\mathrm{p}>0.05$ and less times, $\mathrm{p}<0.001$ ). Frequent visitors perceive more social value and show stronger recommendation intention than infrequent visitors (frequent visitors, $\mathrm{p}>0.05$ and less frequent, $\mathrm{p}>0.05$ ), while participants who spend more time did not perceive social value strong enough to influence their recommendation intention (more times, $\mathrm{p}>0.05$ and less times, $\mathrm{p}>0.05$ ).

Table 6. Online Travel Community Multi-group Analysis Result

\begin{tabular}{lll}
\hline Variable Relationship & $\mathrm{A}$ & $\mathrm{B}$ \\
\hline $\mathrm{FV}^{*}$ Male $^{\mathrm{a}}$ vs Female $^{\mathrm{b}}->\mathrm{RI}$ & $5.35^{* * *}$ & $4.65^{* * *}$ \\
$\mathrm{FV}^{*}$ Older $^{\mathrm{a}}$ vs Younger $^{\mathrm{b}}$-> RI & $4.65^{* * *}$ & $7.37^{* * *}$ \\
$\mathrm{HV}^{*}$ Frequent visitors $^{\mathrm{a}}$ vs Less Frequent Visitors $^{\mathrm{b}}$-> RI & $5.34^{* * *}$ & $3.54^{* * *}$ \\
$\mathrm{HV}^{*}$ More Times $^{\mathrm{a}}$ vs Less Times $^{\mathrm{b}}$-> RI & 1.57 & $6.01^{* * *}$ \\
$\mathrm{SV}^{*}$ Frequent visitors $^{\mathrm{a}}$ vs Less Frequent Visitors $^{\mathrm{b}}$-> RI & 1.83 & 1.26 \\
$\mathrm{SV}^{*}$ More Times $^{\mathrm{a}}$ vs Less Times $^{\mathrm{b}}$-> RI & 0.68 & 1.70 \\
\hline
\end{tabular}

Notes: Significant levels *** $<<0.001$; FV: Functional Value; HV: Hedonic Value; SV: Social Value

RI: Recommendation Intention

\section{Discussion}

The objective of this study was to develop and test a model that examines the impact of customer value framework on recommendation intention and how the perceived 
value influence different customer segments to recommend the online travel communities. Three main hypotheses were proposed and a test of multi-group analyses. The three hypotheses relate to the structural model while multi-group analyses examine how different customer segments respond to customer value framework and its effect to their recommendation intention. Thus, functional value, hedonic value and social value showed positive relationship with recommendation intention. Value is at the fabric of consumers' relationship with service providers and destinations, as such services or places perceived to offer value will ultimately be recommended ( $\mathrm{Li}$, Lee and Yang, 2019). Additionally, functional value demonstrated the strongest relationship with recommendation intention compared to social and hedonic value. This finding also corroborates Ben-Shaul and Reichel (2018, p.462) who contended that "the stronger the functional motive, the greater were all the various aspects of participation-frequency of visits, duration of visits, exposure to others' eWOM, and contribution to knowledge." The study also found that while males were impacted more by functional value to recommend the platform, the relationship between functional value and recommendation intention had less effect on older users than younger users. Similarly, frequent visitors who perceive hedonic value demonstrated greater effect on recommendation intention than infrequent visitors. This finding also aligns with extant studies, for instance $\mathrm{Xu}$, Peak and Prybutok (2015), who, in the context of mobile applications, found that hedonic benefits has effect on recommendation intention. Finally, the link between social value and recommendation intention was positive through frequent visitors. As argued by Lee and Hyun (2018), individuals with weak social ties will perceive more pleasure in online communities, thus, will visit the online communities more frequently than others.

\section{Implications and limitations}

Practically, this study contributes to the OTC literature by developing a model that tests the role of customer value framework on recommendation intention. Firms annually spend huge sums of money on advertising to recruit new customers, whereas customer recommendation remains one of the most potent weapons to recruit new customers $(\mathrm{Ku}$, 2011; Xu, Peak and Prybutok, 2015). Accordingly, our study makes a novel contribution by explicating how the typologies of customer value framework influence recommendation intention. Furthermore, the variables of customer characteristics introduce a new perspective to the OTC literature by highlighting how different customer segments perceive customer value framework and its effect on recommendation intention. Extant studies (Chan, Cheung, Shi and Lee, 2015; Ben-Shaul and Reichel, 2018) have explained the interrelationships of these variables on general social media. To the best of our knowledge, the current study is the first to test different customer characteristics in customer value framework and recommendation intention.

From a practical perspective, our conceptual framework offers managers and administrators of OTCs critical insights and levers on how existing customers can valorize their platforms by recommending it to none members. For company owned OTCs, platform managers like hotel OTCs should regularly post information on various services particularly newly created ones such as cuisines, sporting activities, new luxury cars and 
fishing trips. OTCs can target specific customer segments. Our findings highlight that younger consumers are more susceptible to these services. Thus, focusing on this customer segment will not only attract them but also through peer-influence, which is more dominant among young consumers, they will be able to generate huge followership on the platform. Similarly, independent OTCs should encourage the posting of vital information from different hospitality and tourism services that aid members in their travel decisions. To increase social and hedonic value, managers should regularly organize offline activities and embed entertainment and pleasure-fulfilling content on their platforms and primarily target frequent visitors to the platform.

One of the limitations of our study is that some scales were dropped from the measurements because they could not meet the threshold. This could have implications on our results. Finally, since our sample was obtained from members of Amazon Mechanical Turk, many of them are motivated to participate in the study mainly because of pecuniary interests. It is likely that a neutral sample could have a different result. In spite of these limitations, we believe that our study offers interesting perspective to managers and extends the OTC literature by introducing the interrelationships between customer value framework, recommendation intention and customer characteristics.

\section{References}

Ku EC (2011) Recommendations from a virtual community as a catalytic agent of travel decisions. Internet Res 21(3):282-303

2.

Jung H, Lee G, Hur K, Kim TT (2018) Online travel information value and its influence on the continuance usage intention of social media. Serv Bus 12(1):85-120

3.

Lee HA, Law R, Murphy J (2011) Helpful reviewers in TripAdvisor, an online travel community. J Travel Tour Mark 28(7):675-688

4.

Ben-Shaul M, Reichel A (2018) Motives, modes of participation, and loyalty intentions of Facebook tourism brand page consumers. J Travel Res 57(4):453-471

5.

Lee KH, Hyun SS (2018) The effects of tourists' knowledge-sharing motivation on online tourist community loyalty: the moderating role of ambient stimuli. Curr Issues Tour 21(13):1521-1546

6.

Smith JB, Colgate M (2007) Customer value creation: a practical framework. J Mark Theory Pract 15(1):7-23 
7.

Jung Choo H, Moon H, Kim H, Yoon N (2012) Luxury customer value. J Fash Mark Manag: Int J 16(1):81-101

8.

Shi W, Tang L, Zhang X, Gao Y, Zhu Y (2016) How does word of mouth affect customer satisfaction? J Bus Ind Mark 31(3):393-403

9.

Zhang M, Guo L, Hu M, Liu W (2017) Influence of customer engagement with company social networks on stickiness: mediating effect of customer value creation. Int $\mathrm{J}$ Inf Manage 37(3):229-240

10.

Ukpabi D, Karjaluoto H, Olaleye S, Mogaji E (2019) Influence of offline activities and customer value creation on online travel community continuance usage intention. In: Information and Communication Technologies in Tourism 2019. Springer, Cham, pp $450-460$

11.

Chan TK, Cheung CM, Shi N, Lee MK (2015) Gender differences in satisfaction with Facebook users. Ind Manag Data Syst 115(1):182-206

12.

Li L, Lee KY, Yang SB (2019) Exploring the effect of heuristic factors on the popularity of user-curated 'best places to visit' recommendations in an online travel community. Inf Process Manage 56(4):1391-1408

13.

Zeithaml VA (1988) Consumer perceptions of price, quality, and value: a means-end model and synthesis of evidence. J Mark 52(3):2-22

14.

Holbrook MB (2005) Customer value and autoethnography: subjective personal introspection and the meanings of a photograph collection. J Bus Res 58(1):45-61

15.

Xu C, Peak D, Prybutok V (2015) A customer value, satisfaction, and loyalty perspective of mobile application recommendations. Decis Support Syst 79:171-183

16.

Rintamäki T, Kanto A, Kuusela H, Spence MT (2006) Decomposing the value of department store shopping into utilitarian, hedonic and social dimensions: evidence from Finland. Int J Retail Distrib Manag 34(1):6-24 
17.

Wang HY (2016) Predicting customers' intentions to check in on Facebook while patronizing hospitality firms. Serv Bus 10(1):201-222

18.

Lee KH, Hyun SS (2015) A model of behavioral intentions to follow online travel advice based on social and emotional loneliness scales in the context of online travel communities: the moderating role of emotional expressivity. Tour Manag 48:426-438

19.

Deshwal P (2016) Customer experience quality and demographic variables (age, gender, education level, and family income) in retail stores. Int J Retail Distrib Manag 44(9):940-955

20.

Debrand CC, Johnson JJ (2008) Gender differences in email and instant messaging: a study of undergraduate business information systems students. J Comput Inform Syst 48(3):20-30

21.

Kim C et al (2012) Factors influencing Internet shopping value and customer repurchase intention. Electron Commer Res Appl 11(4):374-387

22.

Yang K, Lee H (2010) Gender differences in using mobile data services: utilitarian and hedonic value approaches. J Res Interact Mark 4(2):142-156

23.

Mogaji E, Erkan I (2019) Insight into consumer experience on UK train transportation services. Travel Behav Soc 14:21-33

24.

Yu J, Zo H, Kee Choi M, Ciganek A (2013) User acceptance of location-based social networking services: an extended perspective of perceived value. Online Inf Rev 37(5):711-730

25.

Tsai HT, Huang HC, Chiu YL (2012) Brand community participation in Taiwan: examining the roles of individual group, and relationship-level antecedents. J Bus Res 65(5):676-684

26.

Tsai WH, Men LR (2013) Motivations and antecedents of consumer engagement with brand pages on social networking sites. J Interact Advert 3(2):76-87 
27.

Lee H, Reid E, Kim WG (2014) Understanding knowledge sharing in online travel communities: antecedents and the moderating effects of interaction modes. J Hospit Tour Res 38(2):222-242

28.

Berinsky AJ, Huber GA, Lenz GS (2012) Evaluating online labor markets for experimental research: Amazon. com's mechanical turk. Polit Anal 20(3):351-368

29.

Ringle CM, Wende S, Becker J-M (2015) SmartPLS 3. SmartPLS, Bönningstedt. http://www.smartpls.com

30.

Hair JF, Ringle CM, Sarstedt M (2011) PLS-SEM: indeed a silver bullet. J Mark Theory Pract 19(2):139-152

31.

Chin WW, Newsted PR (1999) Structural equation modeling analysis with small samples using partial least squares. In: Hoyle RH (ed) Statistical strategies for small sample research. Sage, Thousand Oaks, pp 307-341

32.

Dijkstra TK (2014) PLS'Janus face - response to professor rigdon's 'rethinking partial least squares modeling: in praise of simple methods'. Long Range Plan 47(3):146-153

33.

Hair JF, Sarstedt M, Ringle CM, Gudergan SP (2018) Advanced issues in partial least squares structural equation modeling (PLS-SEM). Sage, Thousand Oaks

34.

Fornell CD, Larcker F (1981) Evaluating structural equation models with unobservable variables and measurement errors. J Mark Res 18(1):39-50

35.

Sarstedt M, Henseler J, Ringle CM (2011) Multi-group analysis in partial least squares (PLS) path modeling: alternative methods and empirical results. Adv Int Mark 22:195218

36.

Hair JF, Hult GTM, Sarstedt M, Ringle C (2014) A primer on partial least squares structural equation modeling (PLS-SEM). SAGE Publications, Thousand Oaks 